\title{
The Starch-Gel \\ Electrophoresis of Glucose-6-phosphate Dehydrogenase and Glyceraldehyde-3-phosphate Dehydrogenase of Streptococcus faecalis, S. faecium and S. durans
}

\author{
By R. A. D. WILLIAMS AND EILEEN BOWDEN \\ Department of Biochemistry, London Hospital Medical College, \\ Turner Street, and Biochemistry Laboratory, London Hospital \\ Dental Institute, Stepney Way, London, E. I
}

(Accepted for publication I2 August 1967)

\begin{abstract}
SUMMARY
Thirty-six strains of enterococci were examined by standard physiological tests. The soluble proteins of cell-free extracts were separated by electrophoresis in starch gels. Specific staining technique for glucose-6-phosphate dehydrogenase and glyceraldehyde-3-phosphate dehydrogenase were applied to the gels. The results of electrophoresis supported the subdivision of the group into two major divisions represented by Streptococcus faecalis and $S$. faecium, with $S$. durans as a variant of $S$. faecium. It was possible tentatively to identify three strains which did not fit well into the taxonomic scheme used.
\end{abstract}

\section{INTRODUCTION}

The enterococci have been subdivided into several named subgroups of which two, Streptococcus faecalis and S. faecium, are regarded by some workers (Deibel, Lake \& Niven, 1963; Deibel, 1964; Whittenbury, 1965) as separate species. Streptococcus zymogenes and $S$. liquefaciens are considered to be varieties of $S$. faecalis, and $S$. durans to be a variety of $S$. faecium. Colobert \& Blondeau (1962) and Defayolle \& Colobert (1962) found that none of the physiological properties used in taxonomy were exclusive to any of the named types, and therefore preferred to regard the enterococci as one species, $S$. faecalis, with two major subdivisions, $S$. faecalis proprium and $S$. faecium. The techniques of electrophoresis and protein or enzyme staining have recently been applied to the differentiation and taxonomy of micro-organisms. Wagman, Pollack \& Maio (1959) found that the pattern of soluble proteins after electrophoresis in liquid media differed amongst several micro-organisms studied. The more convenient technique of gel electrophoresis has been used to show differences in protein pattern amongst the pleuropneumonia-like organisms (Fowler, Coble, Kramer \& Brown, 1963) and in streptomyces (Gottlieb \& Hepden, 1966). The pattern of esterase bands on starch gels was used by Norris (1964) to classify strains of Bacillus thuringiensis. Heterogeneity of glyceraldehyde-3-phosphate dehydrogenase (Ga3 PD) was observed amongst the enterococci (Williams, 1964) and considerable strain variation of glucose-6-phosphate dehydrogenase (G6PD) was also found in this group (Williams, 1965). Little variation was found in the case of 6-phosphogluconate dehydrogenase, or with a stain designed to locate pyruvate kinase that has since been 
proved to reveal adenylate kinase and has been simplified for this purpose. The lactic dehydrogenase pattern in these organisms showed some strain variation, but bands could not be detected at all in some strains by the staining method used. Techniques similar to those of Norris have since been applied to mycobacteria (Cann \& Willox, 1965; Cann, Hobbs \& Shewan, 1966) and to the enterococci (Lund, 1965). In the present work the two enzymes found to vary most in the earlier work (Ga 3 PD, G6PD) have been re-examined for electrophoretic heterogeneity by using 36 enterococcal strains, which were also tested by normal physiological methods.

\section{METHODS}

Organisms. The strains used and their sources are listed in Table I. All were grown on blood agar plates aerobically at $37^{\circ}$ for $24 \mathrm{hr}$ and the whole crop of organisms suspended in I ml. of Oxoid Nutrient Broth no. 2 containing glucose $5 \mathrm{~g} . / 1$. and bovine serum (Oxoid) $50 \mathrm{ml}$./1. One drop (0.03 ml.) quantities of suspension were freeze-dried and the ampoules stored at $4^{\circ}$ until required.

Media. Peptone water for the determination of growth at $50^{\circ}$ contained (g./1.): 20, peptone (Evans); 5, yeast extract (Difco); 5, sodium chloride; I, disodium hydrogen phosphate; I, glucose.

Table I. Sources of strains of enterococci used

\begin{tabular}{|c|c|}
\hline Strain & Source \\
\hline $\begin{array}{l}\text { z93, s I6I, H69D5, s4I, HGH 5I I, 2703, 60, } \\
\text { s32, s43, 98D }\end{array}$ & R. Whittenbury \\
\hline R $26, \mathrm{~K} 2 \mathrm{~A}, \mathrm{FB} 82, \mathrm{I}$ GAU, K 8 A, R 5 & R. H. Deibel \\
\hline $\mathrm{P}_{17} / 8,5422, \mathrm{C}_{3}$ & B. M. Lund \\
\hline $8886,2707,370,8274,819 I, 699 I$ & NCIB \\
\hline $588,580,942,943,582,712,596$ & NCDO \\
\hline $775,8131,8619$ & NCTC \\
\hline 680 , isolated from human dental plaque & G. H. W. Bowden \\
\hline
\end{tabular}

The basal medium for the physiological tests was (g./l.): 5, Lab-Lemco (Oxoid); 5 , peptone (Evans); 5, yeast extract (Difco); 0.5, Tween 80; 0. I, $\mathrm{MnSO}_{4} .4 \mathrm{H}_{2} \mathrm{O} ; 0.02$, bromcresol purple. This solution was adjusted to $\mathrm{pH} 6.5$ and autoclaved at $12 \mathrm{I}^{\circ}$ for $15 \mathrm{~min}$.

Nutrient broth for harvesting organisms was prepared from a solution containing (g./1.): 20, proteose peptone (Oxoid); 10, yeast extract (Difco); 20, glucose. This solution was made to $\mathrm{pH}_{3} \cdot 0$ with hydrochloric acid, filtered through Whatman no. 4 and no. I papers together, neutralized with sodium hydroxide, diluted to twice the original volume and autoclaved at $108^{\circ}$ for $30 \mathrm{~min}$. on two successive days.

Fermentation of carbohydrates. The basal medium was adjusted to the correct volume to provide the final concentrations stated above, by adding sufficient $100 \mathrm{~g}$. $/ 1$. aqueous carbohydrate solution, previously sterilized by filtration, to give a final concentration of $5 \mathrm{~g}$./1. of arabinose, sorbitol, melezitose, melibiose or mannitol. Three Pasteur pipette drops (O. I ml.) of a growing culture were added to $5 \mathrm{ml}$. medium and incubated at $37^{\circ}$ for $72 \mathrm{hr}$. A positive result was indicated by a distinct yellow colour corresponding to a decrease of one $\mathrm{pH}$ unit or more. Some of the cultures recorded as negative decreased the $\mathrm{pH}$ value by $0.5-0.7$ units. 
Reduction, of 2,3,5-tetrazolium chloride (tetrazolium). Basal medium containing glucose $5 \mathrm{~g}$./I. but no bromcresol purple was adjusted to $\mathrm{pH} 6 \cdot 0$. An aqueous solution of tetrazolium was heated to $100^{\circ}$ for $15 \mathrm{~min}$. and added to the basal medium to a final concentration of $0 . \mathrm{Ig}$./1. Cultures were incubated for $8 \mathrm{hr}$ at $30^{\circ}$ after inoculation as above. A deep magenta colour was regarded as a positive result; negative cultures were slightly pink or colourless.

Tolerance of potassium tellurite. Basal medium was prepared containing (g./1.): I5, agar; 5, glucose; I0, instead of 5 Lab-Lemco (Whittenbury, 1965); no bromcresol purple. A Io g./l. aqueous solution of potassium tellurite was sterilized by filtration and added to the medium at $50^{\circ}$ to give a final concentration of tellurite $0.4 \mathrm{~g} . / \mathrm{l}$. Growing cultures were plated on tellurite agar and incubated at $37^{\circ}$ for $72 \mathrm{hr}$. A positive result was indicated by grey or black colonies; negative cultures did not grow at all.

Growth at $50^{\circ}$. One drop $(0.03 \mathrm{ml}$.) of a $17 \mathrm{hr}$ culture was inoculated into $5 \mathrm{ml}$. peptone water and incubated in a $50^{\circ}$ water bath and examined daily for 7 days. An uninoculated tube was included to serve as a blank for extinction readings. However, this was never necessary since positive cultures gave an increase in turbidity easily perceptible to the eye.

Preparation of cell-free extracts. Freeze-dried specimens were plated on blood agar and incubated aerobically at $37^{\circ}$ for $24 \mathrm{hr}$. A colony was picked off and inoculated into $100 \mathrm{ml}$. nutrient broth and incubated for $17 \mathrm{hr}$ under the above conditions. A smear was examined for purity by plating out and Gram-staining and the bulk culture centrifuged at $4000 \mathrm{~g}$ for $20 \mathrm{~min}$. at $5^{\circ}$. The cocci were washed twice by suspension in $25 \mathrm{ml}$. water and centrifugation at $4000 \mathrm{~g}$ for $10 \mathrm{~min}$. then suspended in I ml. water in a bijou bottle and shaken for 20 min. with I ml. ballotini beads (Jencons, grade II) by using a Griffin flask shaker. The beads were separated by centrifugation at I $100 \mathrm{~g}$ over a Hemmings filter (Gallenkamp, Ltd.,) containing Whatman no. I filter paper. The homogenate was centrifuged at $7000 \mathrm{~g}$ for $\mathrm{Io} \mathrm{min}$. at $5^{\circ}$ and the clear or slightly opalescent supernatant fluid was used for starch-gel electrophoresis.

Starch-gel electrophoresis. A suspension of starch (Connaught Medical Research Labs., Toronto, Canada) in 0.0I M-phosphate buffer ( $\mathrm{pH} \mathrm{7.0)} \mathrm{was} \mathrm{boiled} \mathrm{for} 2 \mathrm{~min}$. and the dissolved gases removed under reduced pressure. The concentration of starch used was that recommended by the manufacturer, being $102 \mathrm{~g}$./1. for one batch and I $20 \mathrm{~g} . / 1$. for a second batch. The volume of the solution was adjusted with freshly distilled water to that before boiling and the liquid then poured into a mould ( $11.5 \times$ $17.5 \times 0.7 \mathrm{~cm}$.) lined with 'Melinex' (I.C.I., Ltd.), allowed to set, and the whole placed in the refrigerator for at least $\mathrm{I} \mathrm{hr}$.

Samples of bacterial extract $(0.06 \mathrm{ml}$.) were pipetted on to $0.5 \times 1.5 \mathrm{~cm}$. strips of Whatman no. 17 filter paper. These strips were placed in a transverse slot $5 \mathrm{~cm}$. from the cathodic end of a starch gel, and the gaps between filled with molten gel of the same composition as the main slab. Six sample strips could be used on each gel. The gel and its Melinex sheets were removed from the mould and placed between metalfaced cooling plates through which was pumped water at $5^{\circ}$. The ends of the gel were linked to reservoirs containing $0 \cdot 10 \mathrm{M}$-phosphate buffer $(\mathrm{pH} 7 \cdot 0)$ by cloth bridges and approximately ro $\mathrm{V} . / \mathrm{cm}$. applied along the gel for $\mathrm{I} \cdot 5 \mathrm{hr}$. At the end of this time the voltage gradient in the gel was measured with a Model 40 Avometer.

The gel slabs were sliced horizontally and the cut surfaces stained for the dehydrogenases G6PD or Ga 3 PD. 
Location of dehydrogenases in electrophoregrams. The oxidation of a substrate catalysed by its dehydrogenase can be coupled to the reduction of tetrazolium in the presence of phenazine methosulphate as mediator. Treatment of an electrophoretrogram with a reagent mixture which includes an appropriate substrate will thus give rise to blue bands (due to the insoluble reduced tetrazolium salt) over areas which contain the dehydrogenase for this substrate. The glucose-6-phosphate (G6P) dehydrogenase was located by using G6P as the substrate (Fildes \& Parr, 1963) and glyceraldehyde-3phosphate $\left(\mathrm{Ga}_{3} \mathrm{P}\right)$ dehydrogenase was located by using fructose-I,6-diphosphate + aldolase (Williams, I964). An extract of streptococcus NCIB 8886 was used on every gel as a standard. The value $R_{8886}$ was calculated for all the bands of G6PD and Ga 3 PD of other strains and also for the minor bands of NCIB 8886 , where

$$
R_{8886}=\frac{\text { distance travelled by a given band } \times \text { IOO }}{\text { distance travelled by the major band of } \mathrm{NCIB} 8886} .
$$

\section{RESULTS}

Physiological tests

Each strain was examined on three or four different occasions for each of the tests except the ability to produce acid from mannitol and the ability to grow at $50^{\circ}$; these tests were done twice. The results obtained are listed in Table 2 . In several instances the results of a given test with a given strain were not uniform. In these cases a positive (or negative) result obtained on two of three, or three of four, occasions was judged to be positive (or negative) rather than variable. Only the tolerance of tellurite by strain 775 and the growth at $50^{\circ}$ by strains 8886 and P I $7 / 8$ were variable on this basis.

Fifteen strains were diagnosed as Streptococcus faecalis of which 8 were unequivocal and 3 showed consistently atypical reactions. These latter were 370 (-ve sorbitol and tellurite resistance) 580 and $469 \mathrm{D} 5$ ( - ve melezitose). Eleven of the 15 strains were able to grow at $50^{\circ}$, which is anomalous for S. faecalis (Sharpe, Fryer \& Smith, 1966), and the results of this test were therefore regarded with caution.

Of the 12 strains allotted to the Streptococcus faecium group 7 had all the properties typical of the group. The other 5 were anomalous in the fermentation of one or two carbohydrates: 8I9I and 86I9 (-ve arabinose), s32 (-ve arabinose and mannitol), IGAU ( - ve melibiose) and 582 ( + ve sorbitol).

Six strains were judged to be Streptococcus durans but of these 4 gave one positive reaction each.

Three strains could not be allotted to any of the three groups on the basis of the tests used. Strain 8274 gave 4 positive results and was definitely not Streptococcus durans, but many of the tests were variable with this strain and it could not be allotted to either $S$. faecium or $S$. faecalis. For the same reason si6r was not $S$. durans but might be regarded as $S$. faecalis, which had failed to resist tellurite and to reduce tetrazolium. Strain 943 could either be regarded as $S$. durans with the atypical ability to ferment mannitol and to grow at $50^{\circ}$, or as $S$. facium that failed to ferment arabinose and melibiose.

\section{Electrophoresis}

Extracts of all 36 strains were prepared, electrophoresed and the dehydrogenases stained by the techniques described above. The most deeply coloured bands were 
invariably detected, but this was not the case with many of the minor bands. The minor bands which most commonly occurred had a slightly slower migration than the major bands. The main finding in the present work was that the major band of both enzymes had a markedly lower mobility in strains of Streptococcus faecium and $S$. durans than in $S$. faecalis strains. Examples of these differences are shown in Pl. I, fig. A for glucose-6-phosphate dehydrogenase, and Pl. I, fig. B for glyceraldehyde-3-phosphate dehydrogenase.

The I 5 strains that were designated Streptococcus faecalis by physiological tests all showed major bands of G6PD with $R_{8886}$ values between 88 and 104, and main bands of Ga3PD of $R_{8886}$ from 97 to 104. The enzymes of the unclassified strain S I6I were also of this fast-migrating type; this strain is probably $S$. faecalis.

\section{Table 2. Results of physiological tests on 36 strains of enterococci}

Each symbol (+ or -) represents one test. Where consistent results were obtained in repeated tests, the numeral in the table indicates the number of repetitions. Where the results of repeat tests differed, the individual results are all scored.

\begin{tabular}{|c|c|c|c|c|c|c|c|c|c|}
\hline \multirow[b]{2}{*}{ Strain } & \multirow[b]{2}{*}{$\begin{array}{l}\text { Reduction } \\
\text { of } \\
\text { tellurite }\end{array}$} & \multirow{2}{*}{$\begin{array}{l}\text { Reduction } \\
\text { of } \\
\text { tetra- } \\
\text { zolium }\end{array}$} & \multicolumn{5}{|c|}{ Acid production from sugars } & \multirow[b]{2}{*}{$\begin{array}{c}\text { Growth } \\
\text { at } \\
50^{\circ}\end{array}$} & \multirow[b]{2}{*}{ Diagnosis } \\
\hline & & & $\begin{array}{c}\text { Arabi- } \\
\text { nose }\end{array}$ & Sorbitol & Melezitose & $\begin{array}{l}\text { Meli- } \\
\text { biose }\end{array}$ & Mannitol & & \\
\hline 8886 & $4+$ & $4+$ & $4-$ & +-++ & $4+$ & $4-$ & $2+$ & +-1 & \\
\hline 2707 & $3+$ & $3+$ & $3-$ & $3+$ & $3+$ & $3-$ & $2+$ & $2-$ & \\
\hline 370 & --+- & $3+$ & $3-$ & $3-$ & $3+$ & $3-$ & $2+$ & $2-$ & \\
\hline 588 & $3+$ & $3+$ & $3-$ & $3+$ & $3+$ & $3-$ & $2+$ & $2+$ & \\
\hline 580 & $3+$ & $3+$ & -+-- & $4+$ & $4-$ & $4-$ & $2+$ & $2+$ & \\
\hline 775 & +--+ & $4+$ & $3-$ & $3+$ & $3+$ & $3-$ & $2+$ & $2+$ & \\
\hline 8131 & $3+$ & $3+$ & $3-$ & $3+$ & $3+$ & $3-$ & $2+$ & $2+$ & \\
\hline z93 & $3+$ & $3+$ & $3-$ & $3+$ & $3+$ & $3-$ & $2+$ & $2+$ & 'faecalis' \\
\hline H69D5 & $3+$ & $3+$ & $4^{-}$ & +-++ & +--- & $4-$ & $2+$ & $2+$ & \\
\hline S4I & $3+$ & +-+ & $3-$ & $3+$ & $3+$ & $3-$ & $2+$ & $2+$ & \\
\hline$R 26$ & $4+$ & $4+$ & $4-$ & $4+$ & $4+$ & $4-$ & $2+$ & $2+$ & \\
\hline $\mathrm{K} 2 \mathrm{~A}$ & $3+$ & $3+$ & $3-$ & $3+$ & $3+$ & $3-$ & $2+$ & $2+$ & \\
\hline FB 82 & $3+$ & $3+$ & $3-$ & $3+$ & $3+$ & $3-$ & $2+$ & $2+$ & \\
\hline 680 & $4+$ & $4+$ & --+- & $4+$ & +-++ & $4-$ & $2+$ & $2-$ & \\
\hline R 5 & $3+$ & $3+$ & $3-$ & $3+$ & $3+$ & $3-$ & $2+$ & $2+$ & \\
\hline 8274 & +-++ & +--- & --+ & +-- & +-- & -++ & $2+$ & $2+$ & \\
\hline si6i & $3-$ & $3-$ & $3-$ & ++- & $3+$ & $3-$ & $2+$ & $2+$ & $?$ \\
\hline 943 & $4^{-}$ & $4-$ & $4-$ & $4-$ & $4-$ & $4-$ & $2+$ & $2+$ & \\
\hline $98 \mathrm{D}$ & $4-$ & $4-$ & $3-$ & $3-$ & $3-$ & $3-$ & $2-$ & $2-$ & \\
\hline $699 I$ & $3-$ & --+ & $3-$ & $3-$ & $3-$ & $3-$ & $2-$ & $2-$ & \\
\hline P 17/8 & $3-$ & $3-$ & +-- & $3-$ & $3-$ & $3+$ & $2-$ & -+ & \\
\hline $\mathrm{C} 3$ & $3-$ & $3-$ & $3-$ & $3-$ & $3-$ & $3+$ & $2-$ & $2-$ & durans \\
\hline 712 & $3-$ & $3-$ & $3-$ & $3-$ & $3-$ & $3-$ & $2+$ & $2-$ & \\
\hline 596 & $3-$ & $3-$ & $3-$ & $3-$ & $3-$ & $3-$ & $2-$ & $2+$ & \\
\hline 8I9I & $3-$ & $3-$ & --+ & -+- & $3-$ & $3+$ & +- & $2+1$ & \\
\hline 8619 & $3-$ & $3-$ & --+ & $3-$ & $3-$ & -++ & $2+$ & $2+$ & \\
\hline HGH 5 I I & $3-$ & $3-$ & -++ & $3-$ & $3-$ & $3+$ & $2+$ & $2+$ & \\
\hline 2703 & $4-$ & $4-$ & -+++ & $4-$ & $4^{-}$ & $4+$ & $2+$ & $2+$ & \\
\hline 60 & $4-$ & $4-$ & -++ & $3-$ & $3-$ & $3+$ & $2+$ & $2+$ & \\
\hline$s_{32}$ & $3-$ & $3-$ & -+- & $3-$ & +-- & $3+$ & $2-$ & $2+$ & 'faecium, \\
\hline S43 & $4-$ & $4-$ & -++ & -+- & $3-$ & -++ & $2+$ & $2+$ & raecium \\
\hline I GAU & $3-$ & $3-$ & +-+ & $3-$ & $3-$ & $3-$ & $2+$ & $2+$ & \\
\hline K $8 \mathrm{~A}$ & $4-$ & $4-$ & $3+$ & $3-$ & $3-$ & $3+$ & $2+$ & $2+$ & \\
\hline 582 & +--- & +--- & -+++ & ++-+ & $4-$ & -+++ & $2+$ & $2+$ & \\
\hline 5422 & $4-$ & $4-$ & +-++ & +--- & $4-$ & $4+$ & $2+$ & $2+$ & \\
\hline 942 & $3-$ & $3-$ & -+++ & $3-$ & $3-$ & -++ & $2+$ & $2+1$ & \\
\hline
\end{tabular}


Eleven of the I2 strains identified as Streptococcus faecium, 5 of the $6 S$. durans strains, and the two unclassified strains 8274 and 943 had G6PD enzymes with mobilities between $R_{8886} 62$ and 75. Strain 583 , which was $S$. faecium according to the physiological tests, and strain 699 I which was identified as $S$. durans both had a G6PD pattern of the $S$. faecalis type however. All the $S$. faecium and $S$. durans strains, together with strains 8274 and 943 were consistent with regard to the mobility of Ga3PD, having $R_{8886}$ values between 67 and 83 .

In two strains of the Streptococcus faecalis group $(8886, R 26)$ there appeared a second band of Ga3 PD of comparable density of colour to the major band typical of the group (Pl. I, fig. B). This band had a much lower mobility $\left(R_{8886}=57\right)$ than the enzyme fractions characteristic of $S$. faecium and $S$. durans; its significance is not known.

In the case of both enzymes the Streptococcus faecalis strains were closely similar to one another in band pattern, while the $S$. faecium and $S$. durans strains showed minor variations in mobility and frequently had double major bands (Pl. I, fig. A, B). These minor variations were shown not to be electrophoretic artifacts by electrophoresis of mixtures of pairs of extracts. In twenty such experiments the G6PD and Ga 3 PD enzymes of two $S$. faecalis strains could not be separated in such mixtures. When $S$. faecalis and either $S$. durans of $S$. faecium extracts were mixed, a marked separation of the characteristic forms was obtained; but $S$. faecium could not be distinguished from $S$. durans in this way. The small differences in $R_{8886}$ value frequently gave rise to separations in such mixtures, but neither the degree nor the frequency of these separations was more marked in $S$. faecium $+S$. durans mixtures than in mixtures of two $S$. faecium extracts or two $S$. durans extracts.

\section{DISCUSSION}

Recent work has shown the value of electrophoretic separation of esterases in the characterization of micro-organisms. Location of dehydrogenases in electrophoretograms, such as those described here, by coupling their action with the reduction of a tetrazolium salt (Williams, I964), provides another character which can be revealed by a technique having several apparent advantages over the esterase method. The natural substrate of each enzyme is used in the dehydrogenase reaction and several different dehydrogenases can be located by including the appropriate substrate in the same basal reaction mixture, whereby the blue reduced tetrazolium locates the specific dehydrogenase band. The comparative simplicity of the band patterns for glucose-6phosphate and glyceraldehyde-3-phosphate dehydrogenases reported here is in contrast with more complex patterns of esterase bands reported by other workers. The number of enzymes demonstrable by tetrazolium reduction can be further extended by coupling the action of pure dehydrogenases, used as reagents in the stain, to other enzymes in the electrophoretograms which produce the substrates for the reagent dehydrogenases. For example, hexokinase may be located by using glucose-6phosphate dehydrogenase as a reagent (Brown, Miller, Holloway \& Leve, 1967). The availability of a number of different stains, each of high specificity for one of the enzymes of carbohydrate metabolism, should prove the value in taxonomic studies. Furthermore, much information is already available on the comparative aspects of dehydrogenase enzymes, including amino acid analyses, coenzyme and coenzyme- 
analogue specificities, electrophoretic mobilities and serological specification (Kaplan, 1965). To compare this existing information with data on the properties of microbial enzymes obtained during taxonomic studies would be both desirable and economical.

The results reported here support the division of the Lancefield Group D streptococci into two subgroups comprising Streptococcus faecalis and its varieties on the one hand, and $S$. faecium and $S$. durans. The electrophoretic similarity amongst strains within each subgroup does not imply identity of structure in the enzyme molecules concerned. Dance \& Watts (1962) showed that electrophoretically identical creatine phosphotransferases gave rise to different peptides on tryptic digestion. In spite of this and of the anomalous mobility of enzymes in a small minority of strains, the large difference in enzyme mobility between the two subgroups and the high degree of similarity between the strains comprising each subgroup makes the electrophoretic patterns highly significant taxonomically.

The authors are grateful to the Medical Research Council for financial support and to Drs R. Whittenbury, R. H. Deibel and B. M. Lund for kindly giving strains.

\section{REFERENCES}

Brown, J., Miller, D. M., Holloway, M. T. \& Leve, G. D. (I967). Hexokinase isoenzymes in liver and adipose tissue of man and dog. Science, N.Y. 155, 205.

CanN, D. C. \& Willox, M. E. (1965). Analysis of multimolecular enzymes as an aid to the identification of certain rapidly growing mycobacteria, using starch gel electrophoresis. J. appl. Bact. 28, 165 .

CanN, D. C., Hobbs, G. \& Shewan, J. M. (1966). The identification of certain Mycobacterium species. In Identification Methods for Microbiologists. Ed. by B. M. Gibbs and F. A. Skinner, p. 97. London: Academic Press.

Colobert, L. \& Blondeau, H. (1962). L'espèce Streptococcus faecalis. I. Étude de l'homogénéité par la méthode Adansonniene. Ann. Inst. Pasteur. Paris 103, 345.

DANCE, N. \& WATTS, D. C. (1962). Comparison of creatine phosphotransferase from rabbit and brown-hare muscle. Biochem. J. 84, I14P.

Defayolle, M. \& Colobert, L. (1962). L'èspece Streptococcus faecalis. 2. Étude de l'homogénéité par l'analyse factorielle. Annls Inst. Pasteur, Paris 103, 505.

Deibel, R. H. (I964). The group D streptococci. Bact. Rev. 28, 330.

Deibel, R. H., LAKe, D. E. \& NIVEN, C. F. JUN. (I963). Physiology of the enterococci as related to their taxonomy. J. Bact. 86, I 275.

FILDES, R. A. \& PARR, C. W. (1963). Starch-gel electrophoresis of red cell glucose-6-phosphate dehydrogenase. Biochem. J. 87, $45 \mathrm{P}$.

Fowler, R. C., Coble, D. W., Kramer, N. C. \& Brown, T. MCP. (1963). Starch gel electrophoresis of a fraction of certain of the pleuropneumonia-like group of micro-organisms. J. Bact. 86, I 145.

GotTliEb, D. \& HePDEN, P. M. (1966). The electrophoretic movement of proteins from various streptomyces species as a taxonomic criterion. J. gen. Microbiol. 44, 95 .

Kaplan, N. O. (1965). Evolution of dehydrogenase. In Evolving Genes and Proteins. Ed. by V. Bryson and H. J. Vogel, p. 243. New York: Academic Press.

LUND, B. M. (1965). A comparison by the use of gel electrophoresis of soluble protein components and esterase enzymes of some Group D streptococci. J. gen. Microbiol. 40, $4 \mathrm{I} 3$.

NorRIS, J. R. (1964). The classification of Bacillus thuringiensis. J. appl. Bact. 2 I, 439.

Sharpe, M. E., Fryer, T. F. \& SMITh, D. G. (1966). Identification of the lactic acid bacteria. In Identification Methods for Microbiologists. Ed. by B. M. Gibbs and F. A. Skinner, p. 65. London: Academic Press.

Wagman, J., Pollock, E. \& Maio, N. J. (1959). Molecular distribution in bacterial cells. In Proc. ist nat. Biophys Conf. Ed. by H. Quastler and H.J. Morowitz, p. 14I, New Haven: Yale University Press. 
WhitTEnBURy, R. (1965). The differentiation of Streptococcus faecalis and S. faecium. J. gen. Microbiol. $\mathbf{3}^{8}, 279$.

Williams, R. A. D. (I964). Location of glyceraldehyde-3-phosphate dehydrogenase in starch gels. Nature, Lond. 203, 1070.

Williams, R. A. D. (I965). The effect of sodium fluoride upon Streptococcus faecalis of the dental plaque. In Advances in Fluorine Research and Dental Caries Prevention. Ed. by J. L. Hardwick, H. R. Held and K. G. Konig, p. 267. London: Pergamon Press.

\section{EXPLANATION OF PLATE}

The two gels shown are stained for glucose-6-phosphate dehydrogenase (A) and glyceraldehyde3-phosphate dehydrogenase (B). In each the bacterial extracts used in each track are identified from left to right.

Fig. A. Streptococcus faecalis $8886 ; S$. faecium HGH 5I I S. faecalis $680 ;$ S. faecium 2703; S. faecalis R 26. The major bands of the three $S$. faecalis strains are all typical $\left(R_{8886}=100\right)$. Strains HGH 5 I I and 2703 had a single and a double band respectively $\left(R_{8886}=64\right)$ at a position characteristic of $S$. faecium and $S$. durans. In other preparations the double major band of 2703 merged into one band as straining proceeded.

Fig. B. S. faecalis 8886; S. durans C 3; s I6I (unclassified strain); 943 (unclassified strain); $S$. faecium 5422. This enzyme migrated faster in all strains than did G6PD. Strains 8886 and $S$ I6I had fastmigrating components characteristic of $S$. faecalis. The densely staining second band $\left(R_{8886}=58\right)$ of 8886 was unique to this strain and $\mathrm{R} 26$. The migration of the major bands of the other three strains shows the minor variations $\left(R_{8886}=74-83\right)$ within the range characteristic of $S$. faecium and $S$. durans. 
Journal of General Microbiology, Vol. 50, No. 2

Plate I
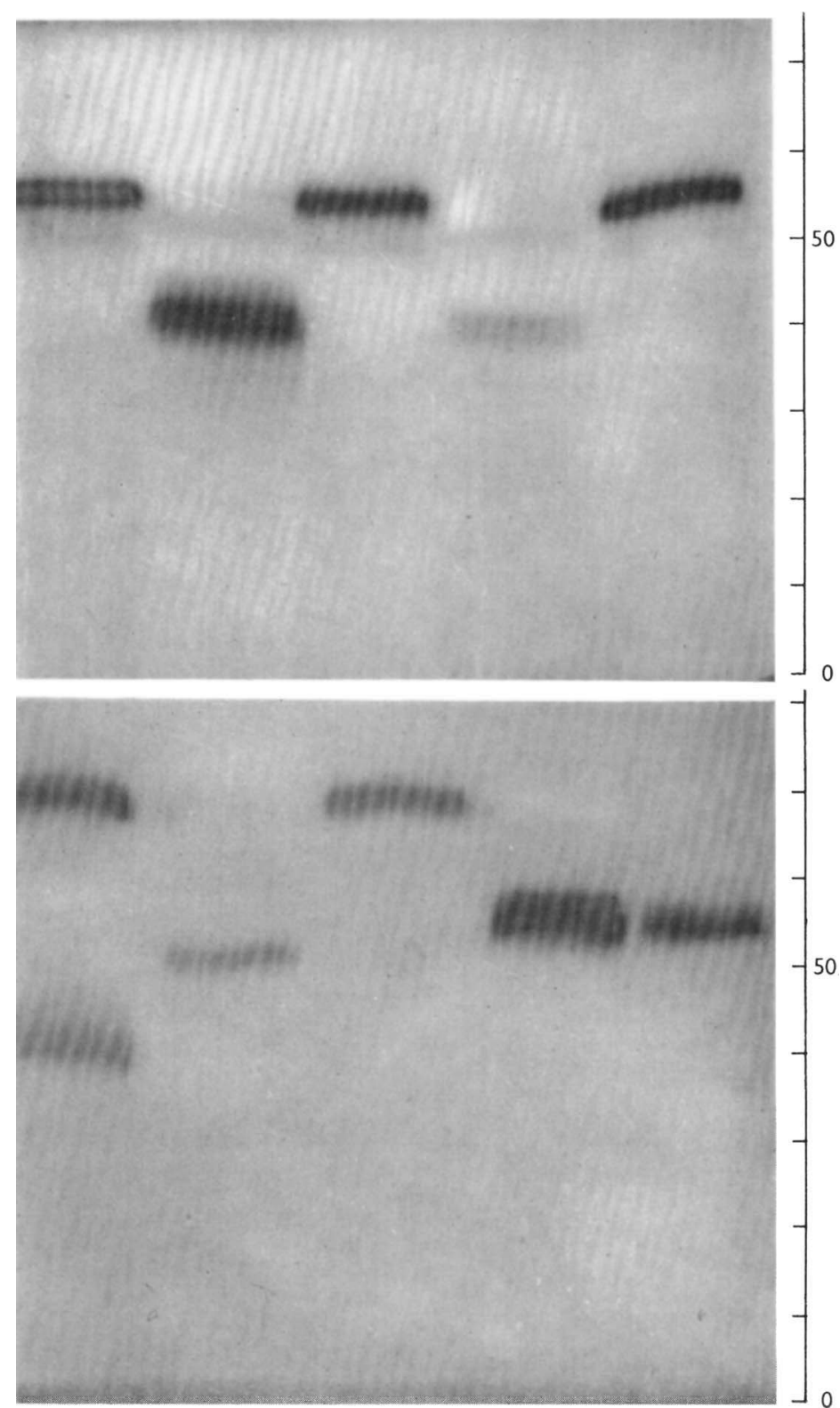

R. A. D. WILLIAMS AND E. BOWDEN

(Facing p. 336) 
